\title{
Effects of Moonlight and Daylight on Hydroacoustic Estimates of Pelagic Fish Abundance
}

\author{
Chris Luecke and Wayne A. Wurtsbaugh \\ Department of Fisheries and Wildlife, Ecology Center \\ Utah State University, Logan, Utah 84322, USA
}

\begin{abstract}
To determine how moonlight and daylight affect hydroacoustic estimates of fish abundance, we used a dual-beam transducer and echo integration to survey pelagic fish (primarily Bonneville ciscoes Prosopium gemmifer) in Bear Lake, Utah and Idaho. During the new moon, the fish were dispersed (not schooling) below the thermocline, chiefly at the depths of 10-20 m. At full moon, they were dispersed but much closer to the bottom, where they were difficult to detect. Acoustic estimates of fish density and biomass during full moons were approximately $50 \%$ of values derived during new moons. A diel survey during a new moon indicated that fish were widely dispersed in the water column at night, but formed schools at dawn. Our study indicated that light conditions must be standardized to insure consistent and comparable population estimates of some pelagic fishes.
\end{abstract}

Acoustic assessments of fish abundance and spatial distribution are becoming commonplace (e.g., Burczynski and Johnson 1986; Rudstam 1988; Brandt et al. 1991; Luecke et al. 1992). The goals of many of these studies are to examine annual changes in sizes of fish populations (Burczynski et al. 1987), to determine the forage fish biomass available for piscivores (Brandt et al. 1991), and to examine spatial and temporal distributions of fish (Levy 1990). As acoustics assessments become more routine, we need to understand how environmental factors may affect the results of acoustic surveys.

One factor that has dramatic effects on fish behavior and spatial distributiors is light intensity. Vertical distributions and diel movements of fish in the pelagic zone are strongly affected by light intensity (Blaxter 1974). Fish foraging activities are also strongly affected by diel (Hobson 1974; Munz and McFarland 1977; Helfman 1981; Wurtsbaugh and Li 1985) and lunar (Gliwicz 1986) cycles of light. Fish spawning activity can be controlled by light-mediated visual cues (Endler 1986) and by diel and lunar changes in light intensity (Robertson et al. 1988). These documented behavioral changes can strongly affect population abundance estimates from hydroacoustic surveys.

Changes in fish behavior due to varying light intensities can bias hydroacoustic analyses and the population estimates derived from them. The shape of the acoustic signal, the depth range analyzed, and the ability to distinguish targets from one another (Patrick et al. 1991) and from the bottom (Burczynski and Johnson 1986) all affect estimates of fish abundance, and these analytical factors change as the distribution of fish in the water column changes.

In this paper, we examine two sources of variation in estimating fish abundance from acoustic surveys. First, we compare the vertical distribution of Bonneville ciscoes Prosopium gemmifer in Bear Lake, Utah and Idaho, during full- and new moon periods at night. Secondly, we examine diel changes in spatial distribution of Bonneville ciscoes revealed by hydroacoustic surveys conducted along one transect continuously from nighttime through the middle of the following day. For both cases we calculate how changes in fish distribution in response to light regimen influence estimates of population size.

\section{Study Area}

Bear Lake is a large (282- $\left.\mathrm{km}^{2}\right)$, oligotrophic lak located at an elevation of $1,805 \mathrm{~m}$ in mountainou terrain on the Utah-Idaho border. Despite lor chlorophyll levels (summer chlorophyll $a, 0.5 \mu \mathrm{g}$ L), Secchi depths are limited to $2-7 \mathrm{~m}$ by mar precipitates in the water column (Birdsey et al 1984; Moreno 1989). During the summer, the to of the thermocline is between 10 and $15 \mathrm{~m}$ deep Oxygen concentrations are high and rarely dro as low as $5 \mathrm{mg} / \mathrm{L}$ in the deep profundal zone (Mo reno 1989). The lake bottom is smooth and ther are few aquatic macrophytes that could confoun a hydroacoustic analysis.

\section{Methods}

In 1990 we established a series of six parall transects in Bear Lake and began an annual acou tic assessment of pelagic forage fish abundano 


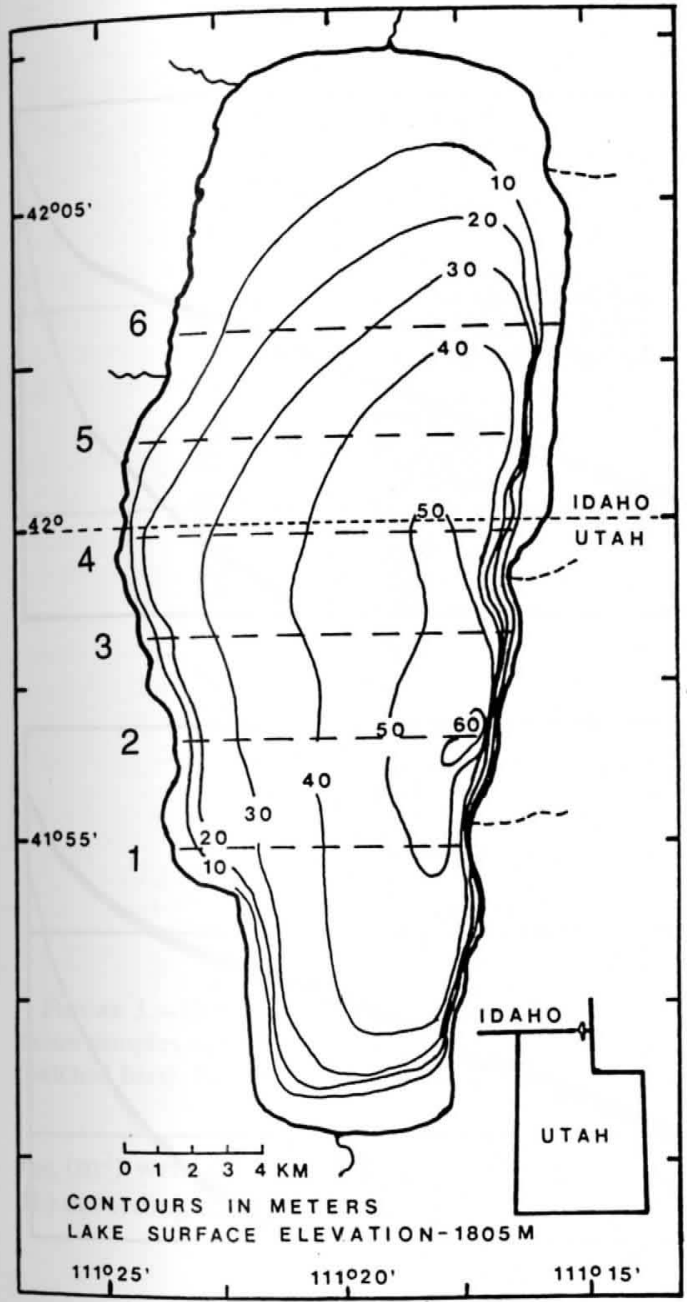

Figure 1.-Map of Bear Lake, Utah and Idaho, showing the hydroacoustic sampling transects used in 1990. Transects 1-6 are numbered along the west shore. Transect 2 was used for the diel comparison on 18 September 1990.

The six transects ran east-west and were separated by 1.5 minutes latitude (Figure 1). Each transect began at the $5-\mathrm{m}$ depth contour on the western shore and extended to the $10-\mathrm{m}$ contour on the precipitous eastern shore. Approximately $50 \mathrm{~min}$

we required to complete each transect.
be anazed the horizontal and vertical distributions of fish targets along these transects to determine spatial heterogeneity and examine changes in fish distribution over time. We examined the abundance and spatial distributions of fish targets under new- and full-moon conditions. The transects were sampled once during the new moon of
TABLE 1.-Standard parameters used in collection and analysis of acoustic data during most sampling transects. Exceptions to these values are noted in the text. The wide-beam noise threshold varied from 100 to $120 \mathrm{mV}$ on different transects.

\begin{tabular}{ll}
\hline \multicolumn{1}{c}{ Parameter } & \multicolumn{1}{c}{ Value } \\
\hline Frequency of sound & $420 \mathrm{kHz}$ \\
Pulse width & $0.4 \mathrm{~ms}$ \\
Pulse frequency & $2 / \mathrm{s}$ \\
Depth range of analysis & $2-60 \mathrm{~m}$ \\
Narrow-beam noise threshold & $70 \mathrm{mV}$ \\
Wide-beam noise threshold & $100-120 \mathrm{mV}$ \\
Bottom threshold & $8 \mathrm{~V}$ \\
Single-target criteria & \\
1/2-peak amplitude & $0.32-0.48 \mathrm{~ms}$ \\
1/4-peak amplitude & $0.40-0.80 \mathrm{~ms}$ \\
\hline
\end{tabular}

26-27 July 1990 and twice during the full moon of 5-6 August 1990. For statistical comparisons, we treated survey results from each transect as an independent replicate. During both periods, the sky was cloudless.

To assess how diel changes in spatial distribution and fish behavior might affect estimates of fish abundance, we analyzed data collected continuously along transect 2 under new-moon conditions on 18 September 1990, beginning at 0107 hours and ending at 1138 hours. Clouds covered approximately $20 \%$ of the sky during the diel sampling.

Although no midwater trawling was conducted with the hydroacoustic surveys, previous and subsequent trawling indicated that more than $98 \%$ of the fish captured in the middle of the water column were Bonneville ciscoes or larval Bear Lake sculpin Cottus extensus (Wurtsbaugh and Neverman 1988; Neverman 1989; Wurtsbaugh and Luecke 1990). Standard lengths ranged from 20 to $200 \mathrm{~mm}$ for Bonneville ciscoes and from 10 to $25 \mathrm{~mm}$ for Bear Lake sculpin. Because target strengths for larval sculpin were similar to those for zooplankton, we eliminated these small targets from our analyses.

Acoustics samples were collected with a BioSonics model 105 echosounder equipped with a $420-\mathrm{kHz}$ dual-beam $\left(6 \times 15^{\circ}\right)$ transducer that allowed us to estimate fish sizes. We sampled at a rate of two pings per second traveling at a boat speed of 4-6 m/s. Additional information on collection and analysis of acoustic data is presented in Table 1. Target voltages were recorded directly into computer files as digitized echoes, and they were also digitized and recorded on Betamax videotape. A paper chart was used to generate an echogram. 
TEMPERATURE ( $\bullet$ )
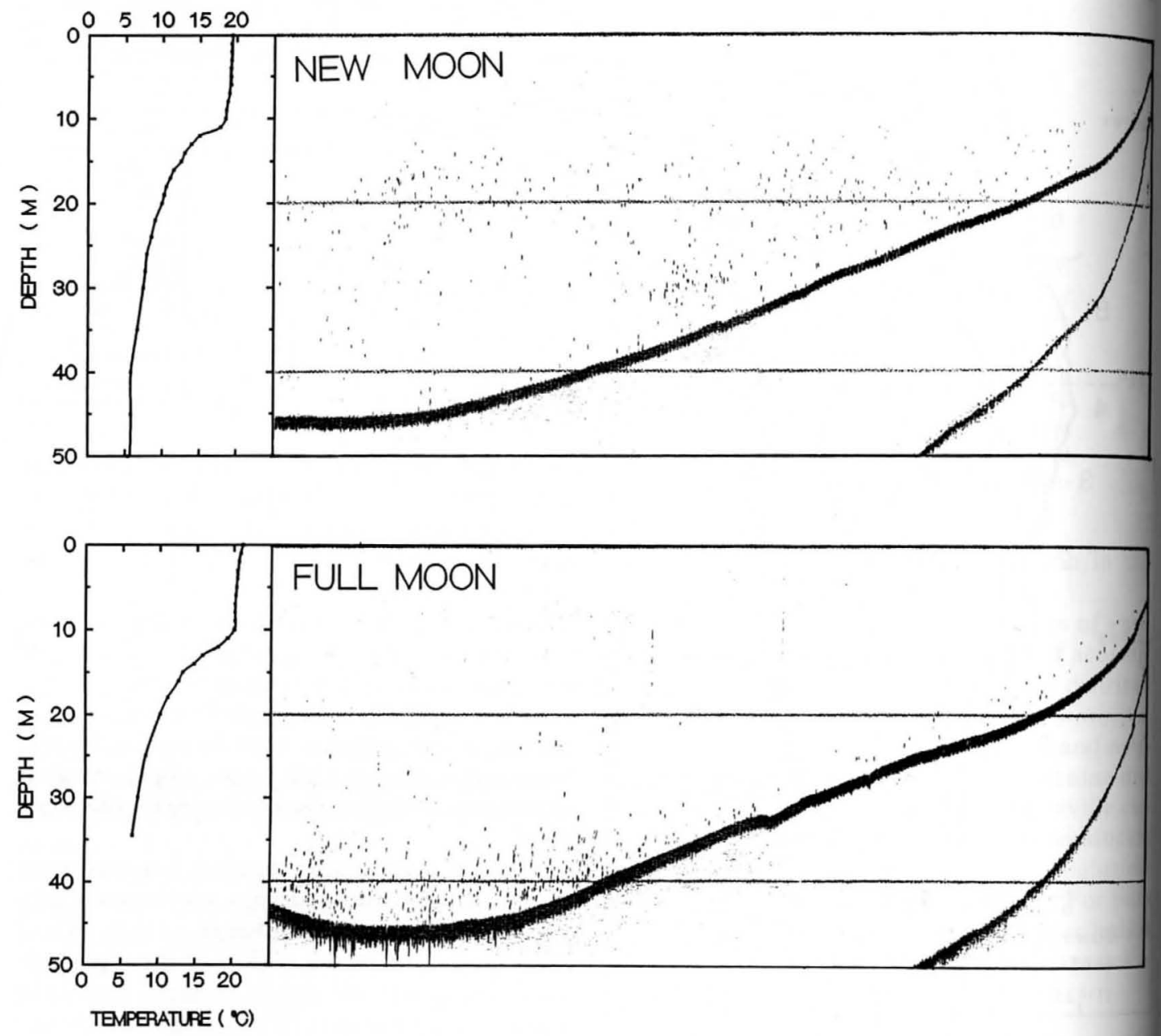

FIGURE 2.-Echogram of a section of transect 5 collected during new- and full-moon periods in Bear Lake. The horizontal scale is approximately $1 \mathrm{~cm}=0.2 \mathrm{~km}$. Vertical temperature profiles are for 31 July 1990 (above) and 14 August 1990 (below).

Data were processed with both echo-counting and echo integration techniques. Echo counting was accomplished with a BioSonics ESP dual beam processor (model 281) and software. Only singlefish targets within $4^{\circ}$ of the acoustic beam axis were used to calculate fish target strength and to obtain fish density estimates. In this report, we use single-fish targets with dual-beam target strengths ranging from -53 to -41 decibels (db). This represents fish of approximately $5-22 \mathrm{~cm}$ total length (TL) (Dahm et al. 1985). Most of these targets should correspond to Bonneville ciscoes older than 1 year. Only echoes that met the singletarget shape criteria used by the analysis software
(Table 1) were selected to calculate densities and target strengths. This procedure may underestimate fish densities, but will not affect distribution patterns if fish aggregations are of similar com. position. Areal fish densities were calculated by first estimating areal densities in each $10-\mathrm{m}$ depth stratum and then summing over these strata.

Echo integration was accomplished with only acoustic information from the narrow-beam transducer, which was processed with a BioSonics ESP model 221 echo integrator. Relative backscattering cross-sectional area $\left(\sigma_{\mathrm{BS}}\right)$ of individual targets from the dual-beam analysis was used to calibrate the echo integration analysis. Values 0 


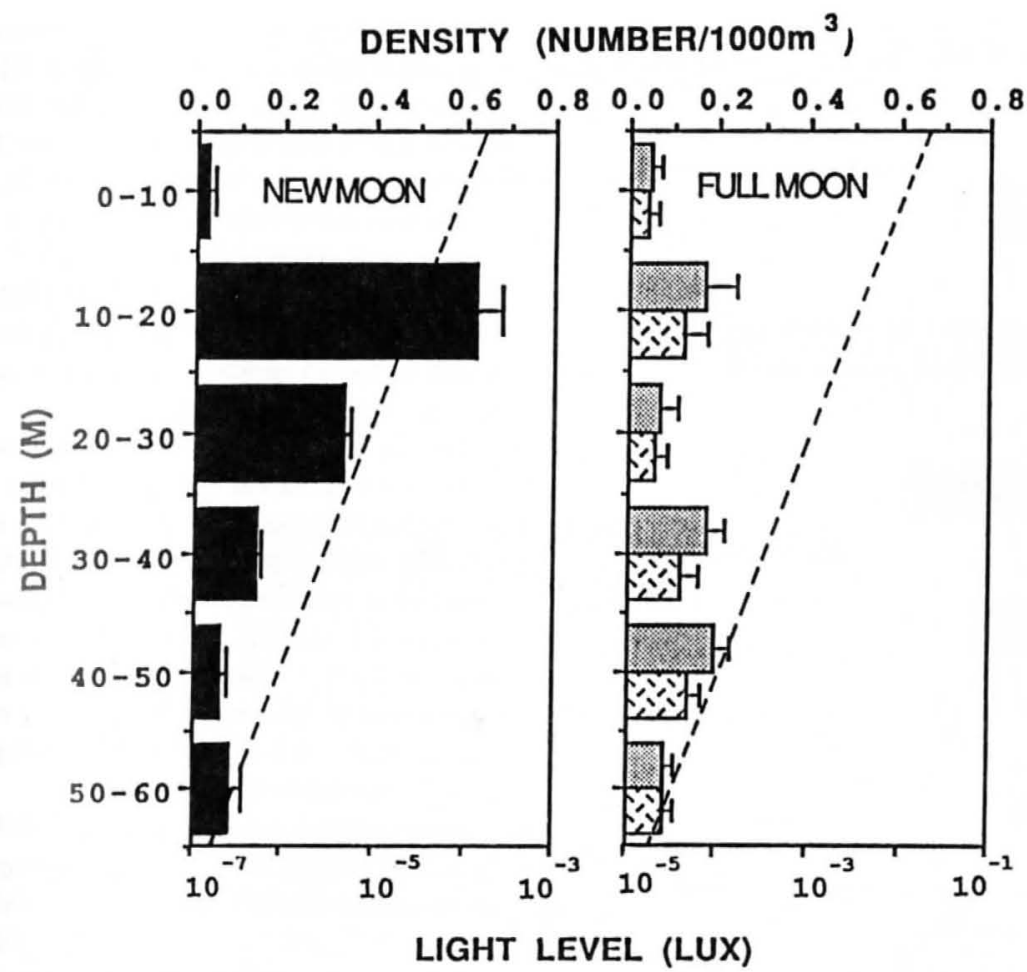

FIGURE 3.-Densities of fish targets at different depths during new- and full-moon periods in Bear Lake. Newmoon samples were collected on 26-27 July 1990 and full-moon samples on 5 August (stippled bars) and 6 August (hatched bars). Error bars indicate $1 \mathrm{SE}$. The dashed line shows light intensity profiles.

$\sigma_{\mathrm{BS}}\left(\mathrm{m}^{2}\right)$ were converted to target strengths (TS, $\mathrm{db}$ ) according to the relationship

$$
\sigma_{\mathrm{BS}}=10^{0.1} \cdot \mathrm{TS}
$$

(BioSonics 1985). The squared voltage output from the echo integration analysis was converted to fish density based on the value of $\sigma_{\mathrm{BS}}$, which corresponds to the voltage returned for the mean-sized fish in the sample. For our analysis, $\sigma_{\mathrm{BS}}$ was 0.000027 , providing a mean target strength of $-45.7 \mathrm{db}$. This value for target strength was then converted to fish total length $(\mathrm{cm})$ based on the relationship

$$
\mathrm{TS}=20 \cdot \log _{10}(\mathrm{TL})-67.7
$$

(Dahm et al. 1985). The constant in the equation of Dahm et al. (1985) was corrected to 67.7 to account for our echosounder frequency of $420 \mathrm{kHz}$. Finally, the total length of the mean-sized fish was converted to mass $(W, \mathrm{~g})$ according to the lengthweight relationship developed for Bonneville ciscoes captured in midwater trawls:

$$
W=0.00212 \cdot \mathrm{TL}^{3.35} \text {. }
$$

With these relationships, the target strength of $-45.7 \mathrm{db}$ corresponded to a fish of $12.6 \mathrm{~cm}$ TL weighing $10.3 \mathrm{~g}$. Echo integration was conducted along transects 2 and 3 (Figure 1) during new- and full-moon conditions.

The bottom of Bear Lake is relatively flat and uniform, and thus a bottom window function could be used for most of each transect. The window depicts the region above the bottom where fish targets were not detectable; it was set at $0.5 \mathrm{~m}$ for echo counting and $1.0 \mathrm{~m}$ for echo integration. The wider window for echo integration guarded against bottom echo intrusion. Along the steep eastern shore of the lake, the bottom window function could not be used. In these areas, the bottom was identified as any target exceeding $6 \mathrm{~V}$. The region above the bottom where fish are difficult to detect is likely larger than the nominal bottom window, especially in regions where the bottom slope is steep.

To estimate light intensities at different depths in Bear Lake, we used vertical extinction coefficients measured from the water surface to the $25-\mathrm{m}$ depth with a LiCor radiometer equipped with a 


\section{BIOMASS (G / $\left.1000 \mathrm{M}^{3}\right)$}

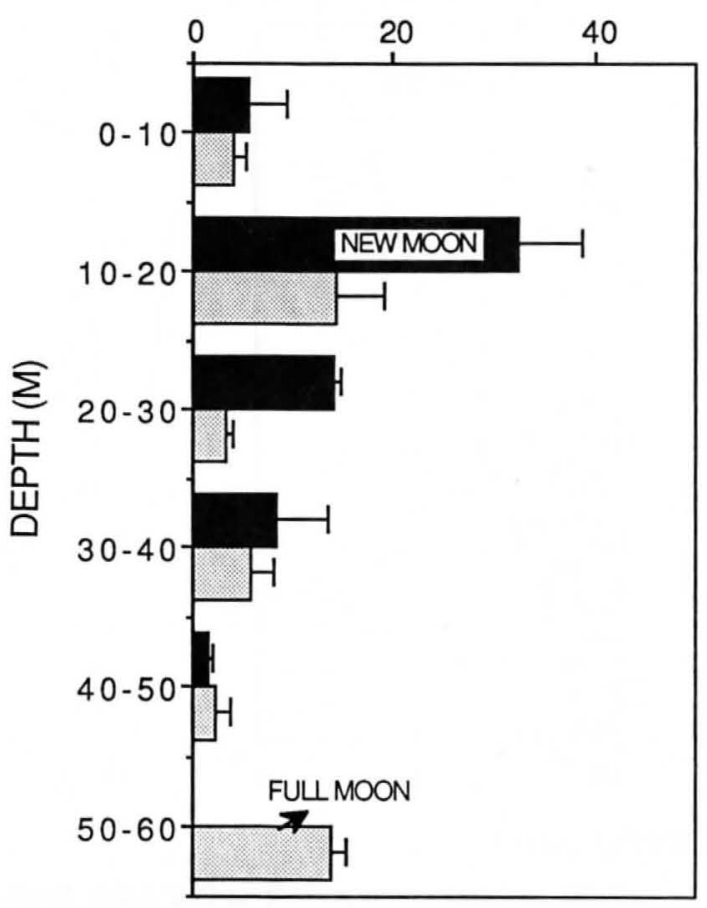

Figure 4.-Biomass of fish sampled along Bear Lake transects 2 and 3 based on echo integration during newmoon (black) and full-moon (stippled) periods in late July and early August 1990 . Mean and the upper range of two transects are depicted.

spherical sensor that measured photosynthetically active radiation. Nighttime surface light intensities were too low to be measured with our radiometer and thus were taken from the computer program of Janiczcek and Young (1987). This program provides estimates of surface light intensities during the night given information on time of day, latitude, longitude, and percent cloud cover. The extinction coefficient was $0.142 / \mathrm{m}$ on $31 \mathrm{July}, 4$ $\mathrm{d}$ after the new-moon survey and $5 \mathrm{~d}$ before the full-moon survey. The extinction coefficient was $0.318 / \mathrm{m}$ on 5 September, $13 \mathrm{~d}$ before the diel survey. The extinction coefficients were relatively constant throughout the top $25 \mathrm{~m}$ of the water columns. Temperatures were measured with a Yellow Springs Instrument thermister (model $58 \mathrm{~A})$.

\section{Results}

Moon phase affected the vertical distribution of fish in Bear Lake. The paper chart recordings in- dicated that during the new-moon survey, fish were dispersed from a depth of about $10 \mathrm{~m}$ (thermo. cline) to the bottom of the lake. Under the full moon, most fish targets were below $30 \mathrm{~m}$ or were associated with the bottom (Figure 2). Surface light intensities were estimated at $2.46 \times 10^{-4} \mathrm{~lx}$ during the new moon and $1.87 \times 10^{-2} \mathrm{~lx}$ during the full moon. It should be noted that echograms such as those depicted in Figure 2 do not correct the width of the expanding echo beam, so deeper targets are overrepresented.

The echo-counting analysis showed that fish density was greatest between depths of 10 and 20 $\mathrm{m}$ during the new-moon sampling and declined steadily with depth (Figure 3). Vertical distributions were similar along all six transects. By multiplying the density of fish targets in each depth stratum by the volume of water in each stratum, we estimated lake-wide abundance of Bonneville ciscoes to be $2.06 \pm 0.43$ million pelagic fish (mean $\pm 95 \%$ confidence limits).

Fish density measured during full-moon conditions was only $51 \%$ of that measured under newmoon conditions (Figure 3 ). Single-fish targets were greatly reduced in the $10-20-\mathrm{m}$ depth stratum compared to new-moon conditions. The highest fish densities were found in the $30-50-\mathrm{m}$ strata during the full moon. Total fish densities estimated from the replicate surveys during the full moon differed by $19 \%$. Whole-lake abundances from the two full-moon surveys were estimated at 0.87 and 0.65 million pelagic fish. An analysis of variance indicated that significant differences in density occurred between new- and full-moon surveys $(F=5.139 ; \mathrm{df}=2,19 ; P \leq 0.05)$. Bartlett's test indicated that variances among groups were similar $(F=0.398 ; \mathrm{df}=2 ; P>0.5)$. A multiple comparison of means (Bonferroni method) indicated that the density estimate from the new-moon survey differed significantly from those of the two full-moon surveys and that the full-moon estimates did not differ from one another.

Analysis of echo integration data from transects 2 and 3 during new- and full-moon conditions indicated that fish biomass was reduced during the full moon (Figure 4). During the full moon, the overall water column biomass decreased by $45 \%$ and a larger proportion of the biomass was in deeper water compared with the new-moon pe riod. The greatest biomass of fish was between 10 and $20 \mathrm{~m}$ during the new moon, whereas most biomass was between 10 and $20 \mathrm{~m}$ and between 50 and $60 \mathrm{~m}$ during the full moon.

During both the new- and full-moon surveys, 


\section{DENSITY ( NUMBER / $1000 \mathrm{M}^{3}$ )}

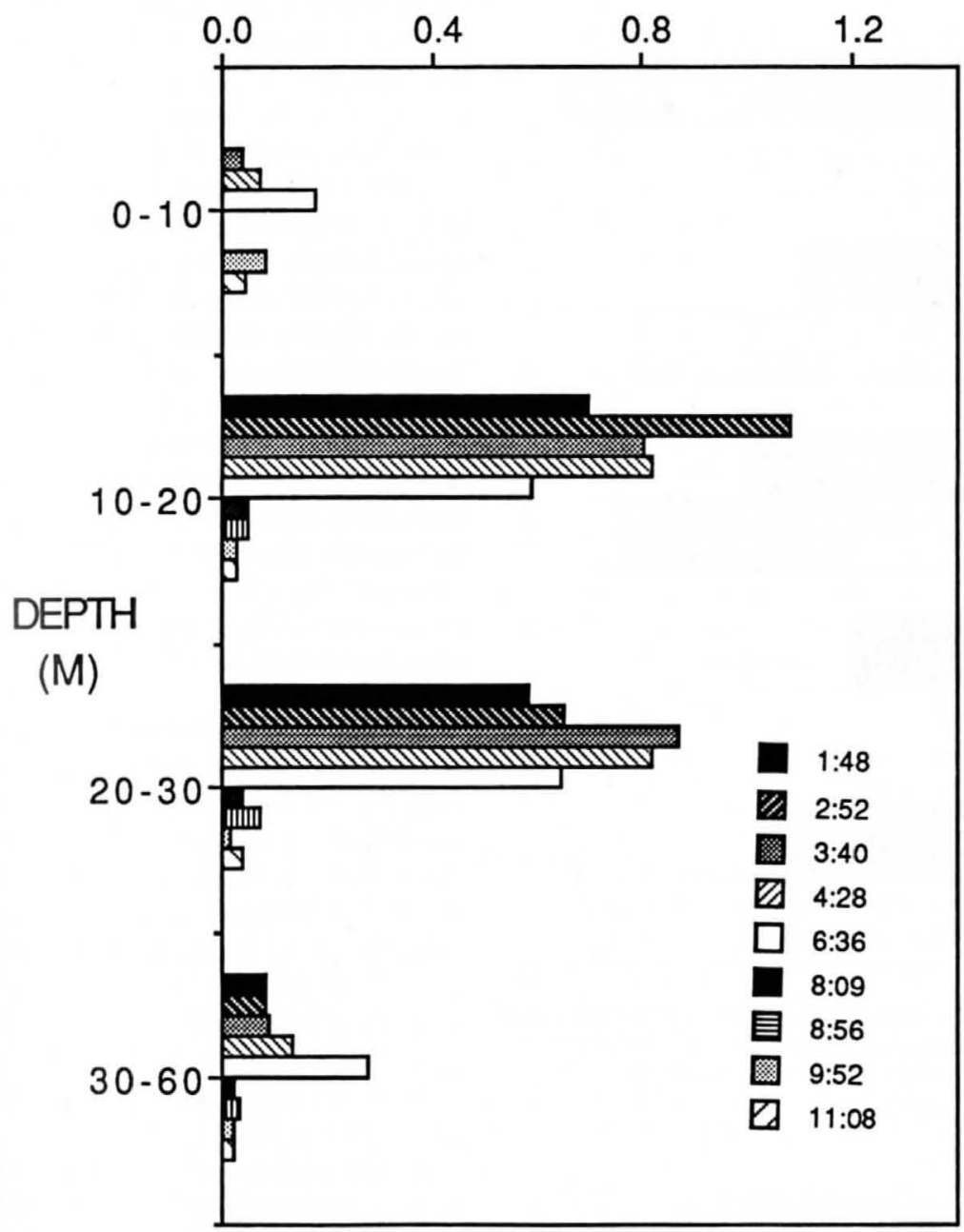

FIGURE 5,-Temporal changes in the density of single-fish targets in different depth strata along Bear Lake transect 2 on 18 September 1990. Times (key) refer to Mountain Daylight Time at the end of a run. Local sunrise occurred at 0642 hours.

densities of single-fish targets were highest at light intensities between $10^{-5}$ and $10^{-4} \mathrm{~lx}$ (Figure 3). During full moon, however, more than $20 \%$ of acoustic targets were at depths where light intensity exceeded $10^{-3} \mathrm{~lx}$. During the diel survey during the new moon of 18 September, when water transparency was reduced and only starlight illuminated the lake, a substantial number of fish were present at light intensities below $10^{-5} \mathrm{~lx}$.

During the diel survey, densities of single-fish targets in the pelagic zone changed relatively little at night but were sharply lower during the day. Between 0100 and 0630 hours, densities of single- fish targets averaged 0.72 and $0.64 / 1,000 \mathrm{~m}^{3}$ within the 10-20- and 20-30-m depth strata, respectively (Figure 5). Few fish were present in the 210- or 30-60-m strata. Dawn (first light) occurred around 0605 hours and local sunrise at 0642 hours on 18 September 1990. After 0636 hours, densities of single-fish targets decreased to fewer than $0.05 / 1,000 \mathrm{~m}^{3}$ and were similar across all depths. Echo integration of the diel survey data indicated that overall biomass of fish in the water column was similar before and after dawn (Figure 6). Fish biomass along transect 2 was estimated to be 0.46 $\mathrm{kg}$ /hectare just before dawn ( 0428 hours) and 0.50 


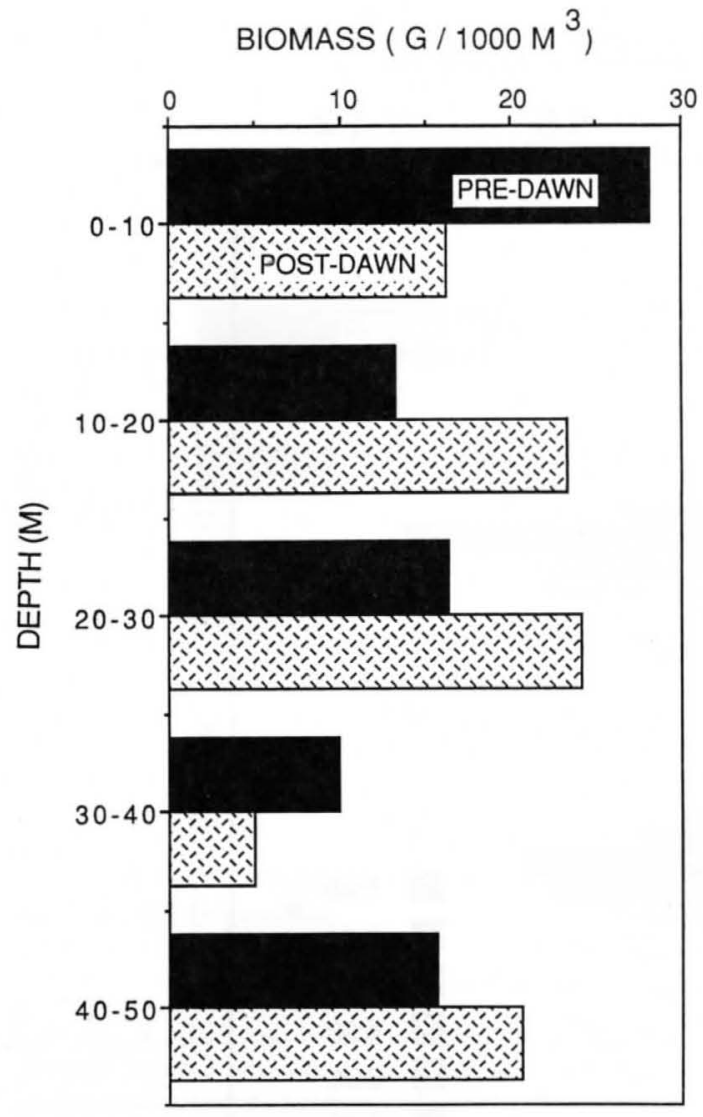

FIGURE 6. - Echo integration estimates of fish biomass along Bear Lake transect 2 collected before sunrise (05480636 hours, dark bars) and $1.5 \mathrm{~h}$ after sunrise (0814 0856 hours, hatched bars).

$\mathrm{kg} /$ hectare just after sunrise (0809 hours). The paper chart recordings indicated that fish were more congregated after sunrise, but no clear change in vertical distribution occurred.

\section{Discussion}

Population estimates of pelagic fish were significantly reduced under full-moon compared with new-moon conditions. Several possibilities could account for this decline. If fish were more closely associated with the substrate during full moon, they may have been indistinguishable from the bottom echo. If so, both echo-counting and echo integration techniques should indicate a reduction in fish abundance during full-moon conditions, and both techniques did so.

Alternatively, increased light intensities during full-moon conditions may have encouraged fish to school (Whitney 1969) and thereby reduce the number of single-fish targets (Patrick et al. 1991) If fish schooling were the primary reason for the reduced fish density during the full moon, biomass estimated from echo integration should have been similar under new- and full-moon conditions. This was not the case, however, in our survey data.

It is also possible that fish congregated in areas where we did not sample intensively during the full-moon period. Our sampling design encompassed pelagic regions of the lake but underrepresented littoral areas. It seems unlikely that Bonneville ciscoes, which are coldwater salmonids, would disproportionately move to warm littoral or near-surface waters $\left(20^{\circ} \mathrm{C}\right)$ during full-moon periods. Indeed, examination of the littoral zone regions that were sampled indicated that fish densities there were low and similar during new and full moons. The bottom of Bear Lake is very uniform and thus it is unlikely that fish could find refuge from higher light intensities by associating with depressions or other types of physical structure.

Our analyses suggested that pelagic fish in Bear Lake moved deeper and became more associated with the bottom during periods of full moon. We know that some Bonneville ciscoes are close to the bottom at night under both new- and fullmoon conditions, because we frequently capture them in small bottom trawls that only sample within $0.5 \mathrm{~m}$ of the substrate. These analyses in dicate that whole-lake population estimates of pelagic fish may be severely biased if fish vary in their association with the bottom during different phases of the moon.

It appears that Bonneville ciscoes move deeper into the water column under full-moon conditions to remain in low light levels at night. Scattering layers in the oceans are also known to descend during full moon (Blaxter 1974). These descents are also likely due to changes in light level.

During both the full- and new-moon surveys. fish were at depths where light intensities were less than $10^{-2} \mathrm{~lx}$. These are levels that generally do not allow planktivorous fish to feed (Blaxter 1980). Consequently, it seems unlikely that the fish were following isolumes that would allow nighttime feeding. More likely, the fish were moving into deeper water under moonlit conditions to avoid predation from piscivores (primarily cutthroal trout Oncorhynchus clarki and lake trout Sal velinus namaycush) that have higher visual sen sitivities and acuities under low-light condition than do smaller fishes (Blaxter 1980; Howick an O’Brien 1983). 
Densities of single-fish targets did not vary greatly between 0100 hours and sunrise during the diel sampling. After sunrise, single-target fish densities declined to values approximately $10 \%$ of nighttime values. Echo integration, however, indicated that similar biomasses of fish were present in the water column before and after sunrise. Information from our chart recordings suggests that echo-counting techniques became unreliable during daylight hours due to increased schooling of fish targets. Ehrenberg and Lytle (1972) also concluded that echo integration is preferable when localized fish densities are high. Although echocounting techniques usually provide more reliable estimates of fish density (Burczynski and Johnson 1986), echo integration may provide reasonable relative biomass estimates, and it may be the only technique possible during daylight.

\section{Acknowledgments}

We thank D. Brandt for his assistance in the field, laboratory, and computer facility, which was critical for completing this project. B. Nielson, P. Birdsey, and D. Driscoll also helped with the field studies. D. Archer, B. Nielson, and P. Birdsey reviewed an earlier draft of the report and made many valuable comments. Funding for the project was provided by the Utah Division of Wildlife Resources and administered by the Utah State Cooperative Fish and Wildlife Research Unit.

\section{References}

BioSonics. 1985. Hydroacoustic assessment techniques. BioSonics, Seattle, Washington.

Birdsey, P., V. Lamarra, and V. D. Adams. 1984. The effect of coprecipitation of $\mathrm{CaCO}_{3}$ and phosphorus on the trophic state of Bear Lake. Pages 229-233 in U.S. Environmental Protection Agency, editor. Proceedings of the International Symposium on Lake and Reservoir Management. USEPA, Knoxville, Tennessee.

Blaxter, J. H. S. 1974. The role of light in the vertical migration of fish-a review. Pages 189-210 in G. C. Evans, R. Bainbridge, and O. Rackham, editors. Light as an ecological factor, II. Blackwell Scientific Publications, Oxford.

Blaxter, J. H. S. 1980. Vision and the feeding of fishes. Pages 32-53 in J. E. Bardach, J. J. Magnuson, R. C. May, and J. M. Reinhart, editors. Fish behavior and its use in the capture and culture of fishes. Proceedings of the conference on the physiological and behavioral manipulation of food fish as production and management tools. International Center for

Biving Aquatic Resources Management, Manila. L. Wells, P. A. Unger, and D. J. Stewart. 1991.
Acoustic measures of the abundance and size of pelagic planktivores in Lake Michigan. Canadian Journal of Fisheries and Aquatic Sciences 48:894908.

Burczynski, J. J., and R. L. Johnson. 1986. Application of dual-beam acoustic survey techniques to limnetic populations of juvenile sockeye salmon (Oncorhynchus nerka). Canadian Journal of Fisheries and Aquatic Sciences 43:1776-1787.

Burczynski, J. J., P. H. Michaletz, and G. M. Marrone. 1987. Hydroacoustic assessment of the abundance and distribution of rainbow smelt in Lake Oahe. North American Journal of Fisheries Management 7:106-110.

Dahm, E., J. Hartmann, T. Lindem, and H. Loffler. 1985. ELFAC experiments on pelagic fish stock assessment by acoustic methods in Lake Constance. EIFAC (European Inland Fisheries Advisory Commission) Occasional Paper 15.

Ehrenberg, J. E., and D. W. Lytle. 1972. Acoustic techniques for estimating fish abundance. Transactions of Geoscience Electronics GE-10:138-145.

Endler, J. A. 1986. Natural selection in the wild. Princeton University Press, Princeton, New Jersey.

Gliwicz, Z. M. 1986. A lunar cycle in zooplankton. Ecology 67:883-897.

Helfman, G. S. 1981. Twilight activities and temporal structure in a freshwater fish community. Canadian Journal of Fisheries and Aquatic Science 38:14051420.

Hobson, E. S. 1974. Feeding relationships of teleostean fishes on coral reefs in Kona, Hawaii. National Marine Fisheries Service Fishery Bulletin 72:915-1031.

Howick, G. L., and W. J. O'Brien. 1983. Piscivorous feeding behavior of largemouth bass: an experimental analysis. Transactions of the American Fisheries Society 112:508-516.

Janiczcek, P. M. J., and A. J. Young. 1987. Computer programs for sun and moon illuminance with contingent table and diagram. U.S. Naval Observatory Circular 171:1-32.

Levy, D. A. 1990. Reciprocal diel vertical migration behavior in planktivores and zooplankton in British Columbia lakes. Canadian Journal of Fisheries and Aquatic Sciences 47:1755-1764.

Luecke, C., L. G. Rudstam, and Y. Allen. 1992. Interannual patterns of planktivory: an analysis of vertebrate and invertebrate planktivores. Pages 275302 in J. F. Kitchell, editor. Food web management: a case study of Lake Mendota. Springer-Verlag, New York.

Moreno, E. G. 1989. Seasonal variation in the species composition, abundance, and size frequency distribution of zooplankton in Bear Lake, Utah-Idaho. Master's thesis. Utah State University, Logan.

Munz, F. W., and W. N. McFarland. 1977. Evolutionary adaptations of fishes to the photic environment. Pages 193-274 in F. Crescitelli, editor. The visual system in vertebrates. Springer-Verlag, New York.

Neverman, D. 1989. The diel vertical migration and feeding of underyearling Bear Lake sculpin Cottus 
extensus (Pisces, Cottidae). Master's thesis. Utah State University, Logan.

Patrick, P. H., B. Sim, and G. Hunt. 1991. Range detection of targets using hydroacoustics in the laboratory. Canadian Journal of Fisheries and Aquatic Sciences 48:290-295.

Robertson, D. R., D. G. Green, and B. C. Victor. 1988. Temporal coupling of production and recruitment of larvae of a Caribbean reef fish. Ecology 69:370 381.

Rudstam, L. G. 1988. Patterns of zooplanktivory in a coastal area of the northern Baltic proper. Doctoral dissertation. University of Stockholm, Stockholm.

Whitney, R. R. 1969. Schooling of fishes relative to available light. Transactions of the American Fisheries Society 98:495-504.

Wurtsbaugh, W. A., and H. W. Li. 1985. Diel migra- tions of a zooplanktovirous fish (Menidia beryllina) in relation to the distribution of its prey in a large eutrophic lake. Limnology and Oceanography 30 : 565-576.

Wurtsbaugh, W., and C. Luecke. 1990. Hydroacoustic and trawl assessment of pelagic fish in Bear Lake, Utah-Idaho. Pages 140-154 in W. Wurtsbaugh and C. H. Hawkins, editors. Trophic interactions be. tween fish and invertebrates in Bear Lake, UtahIdaho. Utah State University, Ecology Center Spe. cial Publication, Logan.

Wurtsbaugh, W. A., and D. Neverman. 1988. Postfeeding thermotaxis and daily vertical migration in a larval fish. Nature (London) 333:846-848.

Received January 7, 1992 Accepted July 21, 1992 